\title{
A Novel Methodology to Extract Voice Signal Features
}

\author{
Saleh Khawatreh \\ AL-Ahliyya AMMAN \\ University
}

\author{
Belal Ayyoub \\ Balqa Applied University
}

\author{
Ashraf Abu-Ein \\ Balqa Applied University
}

\author{
Ziad Alqadi \\ Balqa Applied University
}

\begin{abstract}
A novel methodology to manipulate wave file and create a feature array for each wave file will be introduced, this array can be used later on to recognize the voice file. A set of experiments will be performed in order to prove the uniqueness of the calculated feature array, and that the created feature array for a certain wave file does not match any other feature array for other wave files. The proposed methodology will minimize the efforts of voice recognition by mean of minimizing the time of feature array creation and minimizing the size of the calculated array.
\end{abstract}

\section{General Terms}

Voice recognitions, artificial intelligence

\section{Keywords}

Wave file, feature array, histogram.

\section{INTRODUCTION}

Voice recognition systems have become the important applications for speech recognition technology. In this paper, an animal identification (ID) detection system based on animal voice pattern recognition algorithm has been developed. Voice waveforms (stereo with 2 channels (two column array) or mono with one channel (one column array) are classified according to their amplitude, frequency, and shape, as well as the sites on the scalp at which they are recorded. The most familiar classification uses EEG waveform frequency [1], [2], and [3]. In [4] author used Time Frequency Transforms for signal decomposition in setting frame theory and provides new insights in application to data analysis (see Figure 1), which shows the amplitude of the two channels of the voice wave file bird.wav.

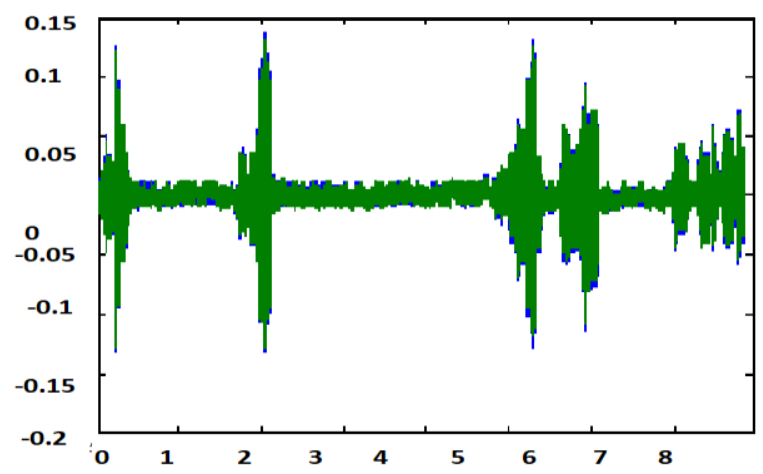

Fig 1: Amplitude of the bird.wav signal

Wave files can be represented histogram, which includes the repetition of each value in wave form of voice signal [5], [6],[7] and [8]. Figure 2 shows the histogram of the bird.wav voice signals with amplitude range value from -0.1319 to 0.1377 .

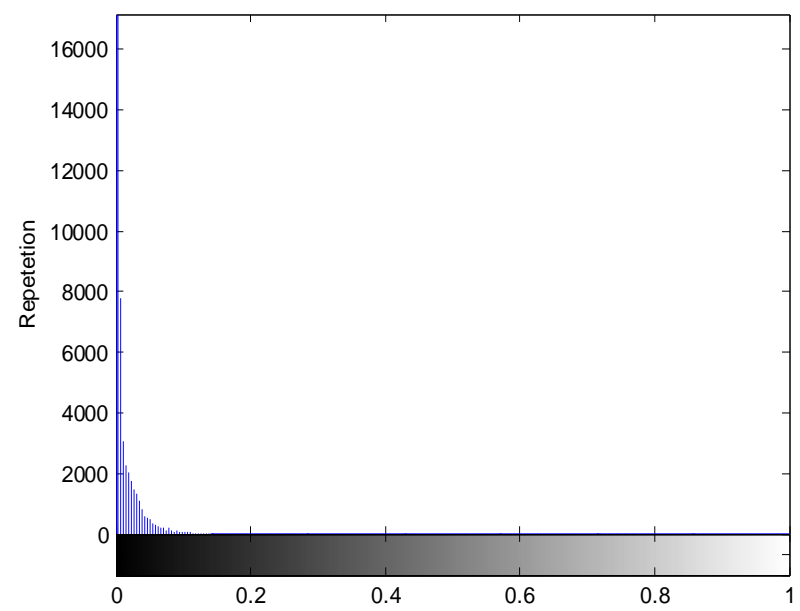

Fig 2: Histogram of the bird.wav

In Figure 2 which illustrating the histogram of the bird.wav signal the main objective of voice recognition system is to understand the spoken information and it must be completely accurate giving a $100 \%$ of recognition ratio. Many developments have been done in the field of voice recognition [9] and mostly all the developed proposed methods are based on: Voice analysis, feature extraction, modeling and matching [10]. These methods [11], [12],[13] and [14] are mostly suffering from the efforts needed to perform the process of voice recognition and the lowest recognition ratio. A method proposed in [15] is a good example of one of the current development which is based on extracting voice features based on voice analysis to calculate some parameters such as estimated population (mu), dynamic range, peak factor, Power spectral density, and zero crossing rate. These parameters require a deep processing and gathering them in one array to create a voice signature leads some time to decrease the recognition system efficiency by reducing the recognition ratio.

\section{THE PROPOSED METHODOLOGY}

The proposed methodology can be implemented applying the following steps:

\subsection{Array features creation and initialization}

Array features (AF) is a 4-element array: the first element reflects the repletion of zeros, the second reflects the repetition of ones, the third reflects the repetition of twos, while the fourth element reflects the repetition of threes. Initially array have to be reset to zeros

\subsection{Prepare the wave file (mono or stereo wave file)}

This step can by implemented by getting the wave file (WF) and converting it from one column (mono file) or from 2 columns to one row file. 


\subsection{For each value in WF p(i) do the following}

2.3.1. Find a logical value $k 0$ using the following equation

$$
K \mathbf{0}=(P(i+1)+P(i-1) \geq 2 P(i))
$$

2.3.2.Find a logical value $k 0$ using the following equation

$$
K 1=(P(i+2)+P(i-2) \geq 2 P(i))
$$

\subsubsection{Find the index of IAF}

$$
I A F=(k 1(2)+K 0+1)
$$

\subsubsection{Add one to AF (IAF)}

Below is a calculated example:

Let us do the calculation for the value pointed by the red:

$$
\begin{array}{rl|l|l|l|}
\hline \mathbf{0 . 0 1 5 3} & \mathbf{0 . 0 1 1 5} & \mathbf{0 . 0 1 1 5} & \mathbf{0 . 0 1 3 4} & \mathbf{0 . 0 0 7 7} \\
\hline \boldsymbol{K 0}=(\boldsymbol{P}(\boldsymbol{i}+\mathbf{1})+\boldsymbol{P}(\boldsymbol{i}-\mathbf{1}) \geq \mathbf{2} \boldsymbol{P}(\boldsymbol{i})) \\
=0.0134+0.0115 \geq 2(0.0115) \\
=0.0249>=0.0230=1 \\
\quad \boldsymbol{K} \mathbf{1}=(\boldsymbol{P}(\boldsymbol{i}+\mathbf{2})+\boldsymbol{P}(\boldsymbol{i}-\mathbf{2}) \geq \mathbf{2} \boldsymbol{P}(\boldsymbol{i})) \\
=0.0077+0.0153 \geq 2(0.0115) \\
=0.0230 \geq 0.0230=1 \\
\text { IAF }=\mathrm{k} 1(2)+\mathrm{k} 0=3
\end{array}
$$

So, add 1 to the repetition of $3(\mathrm{AF}(4)=\mathrm{AF}(4)+1)$

Table 1 shows how the calculated parameters $\mathrm{k} 0$ and $\mathrm{k} 1$ are used to increment the repetition of values from 0 to 3 :

Table 1: Calculated parameters k1 and k0

\begin{tabular}{|c|c|c|}
\hline Parameter k1 & Parameter k0 & $\begin{array}{l}\text { Repetition to } \\
\text { be incremented }\end{array}$ \\
\hline 0 & 0 & 0 \\
\hline 0 & 1 & 1 \\
\hline 1 & 0 & 2 \\
\hline 1 & 1 & 3 \\
\hline
\end{tabular}

\section{IMPLEMNTATION AND RESULTS DISCUSSION}

The mentioned methodology was implemented using Matlab environment, deferent wave file was used. Figure 3 and Figure 4 shows the wave of the two channels of the bird stereo file:

\section{Bird.wav Channel 1}

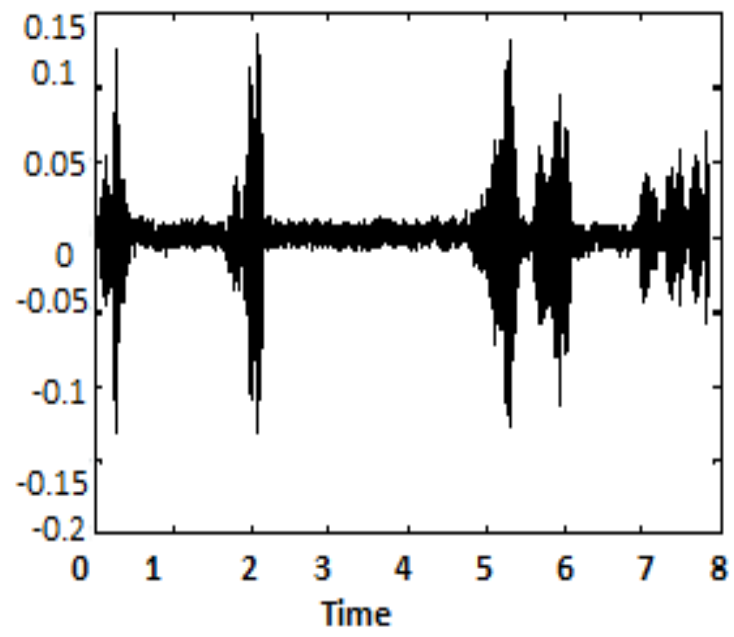

Fig 3: The Bird wave of the first channel

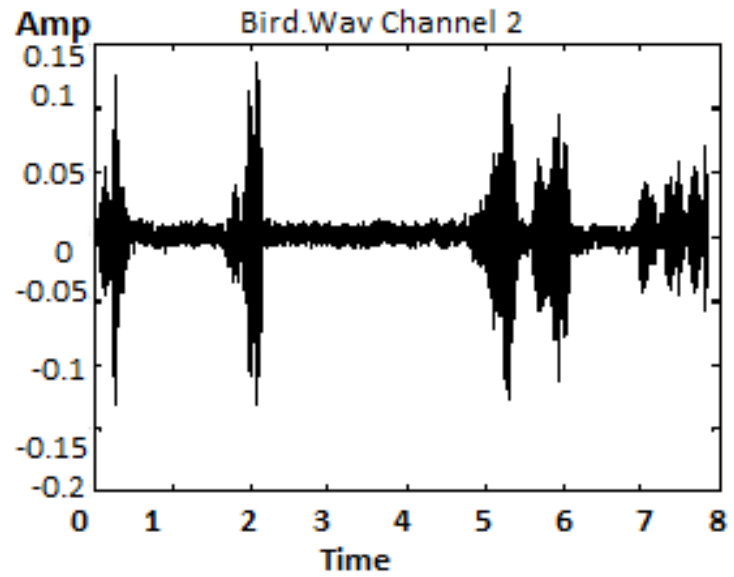

Fig 4: The Bird wave of the second channel

In the table which is illustrated in the section below (see Table 2), all features which extracted for some stereo voices Table 2: Samples of the extracted features for some stereo voices

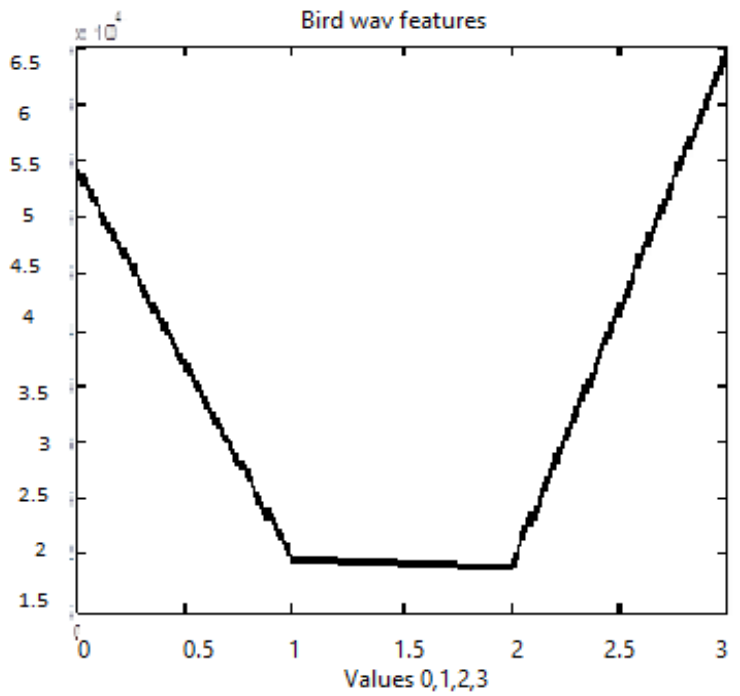

Fig 5: Values 0 to 3 distribution for file bird.wav 
In the Figure 5 which illustrated the distribution of the values 0 to 3 which are to be used as extracted features for the file bird.wav.

From the results shown in Table 2 important Facts can be seen as illustrated below:

- Each wave file has unique features array.

- The features can be used as a signature to recognize the wav file.

- The extracted features are very sensitive to any changes in the wave file, as shown in Table 3, thus signature can be used to discover any distortion in the wave file.

- The proposed methodology is very simple to be implemented thus it reduces the deep processing of voice analysis eliminating the required time needed for voice processing.

- The proposed methodology simplifies the voice histogram by creating a new one consisting of only four values.

- The created feature are which can be used as a voice signature contain only four values, thus the array size is very

Table 2: Samples of extracted features for some stereo voices

\begin{tabular}{|l|l|l|l|l|}
\hline Voice & Feat- & Feat- & Feat- & Feat- \\
file & ure 1 & ure 2 & ure 3 & ure 4 \\
\hline Bird.wav & 54075 & 19533 & 18947 & 64616 \\
\hline Cow.wav & 27260 & 3209 & 3342 & 28112 \\
\hline Cow2.wav & 14438 & 2504 & 1208 & 16833 \\
\hline Dog.wav & 31655 & 11615 & 11091 & 37772 \\
\hline Dolphin.wav & 27757 & 9397 & 8953 & 32476 \\
\hline Donkey.wav & 82767 & 30644 & 29122 & 95450 \\
\hline Duck.wav & 144450 & 50842 & 48556 & 167219 \\
\hline Elephant.wav & 15908 & 5965 & 5245 & 17911 \\
\hline Horse.wav & 12625 & 2319 & 1392 & 14753 \\
\hline
\end{tabular}

Small (32 bytes), so using this array for different voice application will lead to efficient voice processing

Table 3: The methodology sincerity to the changes in the wave file

\begin{tabular}{|l|l|l|l|l|l|}
\hline $\begin{array}{l}\text { Changes in } \\
\text { wave file(only } \\
\text { one element) }\end{array}$ & \multicolumn{5}{|c|}{ Features } \\
\hline Bird.wav & $\begin{array}{l}\text { Before } \\
\text { changes }\end{array}$ & 54075 & 19533 & 18947 & 64616 \\
WF(100)=0 & $\begin{array}{l}\text { After } \\
\text { changes }\end{array}$ & 54075 & 19534 & 18947 & 64615 \\
\cline { 2 - 6 } & & & & & \\
\hline
\end{tabular}

\begin{tabular}{|c|c|c|c|c|c|}
\hline \multirow{2}{*}{$\begin{array}{l}\text { Cow.wav } \\
\text { WF }(100)=0.5\end{array}$} & $\begin{array}{l}\text { Before } \\
\text { changes }\end{array}$ & 27260 & 3209 & 3342 & 28112 \\
\hline & $\begin{array}{l}\text { After } \\
\text { changes }\end{array}$ & 27257 & 3210 & 3344 & 28112 \\
\hline \multirow{2}{*}{$\begin{array}{l}\text { Dog.wav } \\
\text { WF }(220)=0.5\end{array}$} & $\begin{array}{l}\text { Before } \\
\text { changes }\end{array}$ & 31655 & 11615 & 11091 & 37772 \\
\hline & $\begin{array}{l}\text { After } \\
\text { changes }\end{array}$ & 31655 & 11614 & 11091 & 37773 \\
\hline
\end{tabular}

\section{CONCLUSION}

A novel Methodology for voice feature extraction was proposed, it was proved that the methodology very simple and effective and it can be used to create a voice signature which can be used for different application such voice recognition. There is a need to develop new hybrid Methods that will give better performance in robust speech recognition area.

\section{REFERENCES}

[1] Blume WT, Kaibara M. Atlas of Pediatric Electroencephalography. 2nd ed. Philadelphia: Lippincott-Raven; 1999.

[2] Fisch B, Spehlmann R. Fisch and Spehlmann's EEG Primer. 3rd ed. Amsterdam: Elsevier; 1999.

[3] Niedermeyer E, Lopes da Silva F. Electroencephalography :Basic Principles, Clinical Applications, and Related Fields. 5th ed. Baltimore: Williams \& Wilkins; 1993.

[4] Mijail Guillemard, Gitta Kutyniok, Holger Boche, Friedrich Philipp,"Signal Analysis with Frame Theory and Persistent Homology", June 2013.

[5] Ioannides AA, Poghosyan V, Dammers J, Streit M. Realtime neural activity and connectivity in healthy individuals and schizophrenia patients. Neuroimage. 2004 Oct. 23(2):473-82.

[6] Stern JM, Engel J.An Atlas of EEG Patterns. Philadelphia: Lippincott Williams \& Wilkins; 2004.

[7] Barker J., Marxer R., Vincent E., and S. Watanabe, "The third 'chime' speech separation and recognition challenge: Dataset, task and baselines," in 2015 IEEE Workshop on Automatic Speech Recognition and Understanding (ASRU). IEEE, 2015, pp. 504-511.

[8] Johns Hopkins. Pacemakers for the brain. Johns Hopkins Med Lett Health After 50. 2004 Sep. 17(7):1-2

[9] Dastoor, Sarosh K. "Comparative Analysis of Steganographic Algorithms impacting the information in the Speech Signal for enhancing the Message Security in next Generation Mobile devices", (WICT), 2011,), 2011 World Congress on Information and Communication Technologies. IEEE, 2011, pp. 279-284.

[10] Shreya Narang1, Ms. Divya Gupta2, Speech Feature Extraction Techniques: A Review, IJCSMC, Vol. 4, Issue. 3, March 2015, pg.107 - 114.

[11] Santosh K.Gaikwad and Pravin Yannawar, A Review, International Journal of Computer Applications A 
Review on Speech Recognition Technique Volume 10 No.3, November 2010

[12] Rybach, D.; C. Gollan; G. Heigold; B. Hoffmeister; J. Lööf; R. Schlüter; H., Ney September 2009. "The RWTH Aachen University Open Source Speech Recognition

[13] Jaslene, Dawood Dilber, Feature "Selection and Extraction of Audio", International Journal of Innovative Research in Science, Engineering and Technology, Vol. 5, Issue 3, March 2016
[14] Sanjivani S. Bhabad Gajanan K. Kharate International Journal of Advanced Research in Computer Science and Software Engineering, An Overview of Technical an Overview of Technical Progress in Speech Recognition Volume 3, Issue 3, March 2013

[15] Khaled Matrouk, Abdullah Al-Hasanat, Haitham Alasha'ary, Prof Ziad Al-Qadi, Prof Hasan Al-Shalabi Speech Fingerprint to Identify Isolated Word-Person World Applied Sciences Journal 31 (10): 1767-1771, 2014 